\title{
CONCEPTUALISING BUILDING INFORMATION MODELLING FOR CONSTRUCTION EDUCATION
}

\author{
Theophilus OLOWA*, Emlyn WITT, Irene LILL \\ Department of Civil Engineering and Architecture, Tallinn University of Technology, Tallinn, Estonia
}

Received 31 January 2020; accepted 31 March 2020

\begin{abstract}
Digitalisation of the construction industry is both driving changes in construction education to meet emerging industry needs and providing opportunities for new delivery approaches. Universities are responding to these challenges in diverse ways including in their use of Building Information Modelling for construction education (BfCE). This research is aimed at understanding the existing approaches to BfCE. A systematic literature review of BfCE in universities was carried out which identified 305 relevant articles including 44 specific cases of BfCE. These were qualitatively analysed and a Straussian Theory Model (STM) was adopted to understand the different BfCE approaches reported in the literature, the contextual and intervening conditions which give rise to them and their consequences in order to develop a conceptual framework which sets out the relationships between these and the digitalisation of the construction industry. This study provides construction educators with a descriptive typology that depicts all possible BfCE approaches and which could assist them in determining suitable approaches and to conceptualise new approaches for teaching students to use Building Information Modelling (BIM) and also for leveraging BIM to enhance their teaching of other topics.
\end{abstract}

Keywords: Building Information Modelling, BIM education, AEC-FM, Grounded Theory, Straussian Theory Model, systematic literature review, construction education.

\section{Introduction}

Building Information Modelling (BIM) is revolutionising didactic methodologies in construction education at a time when Architectural, Engineering, Construction and Facilities Management (AEC-FM) educators are faced with the challenge of educating students so that their professional roles would properly align with the digitalisation of the construction industry to enhance not only their productivity but also their decision-making ability (Du et al., 2017; Hwang \& Safa, 2017; Tranquillo et al., 2018). Education that is mediated by technological innovations, such as BIM, has been shown to support students' motivation, satisfaction and performance both academically and professionally (Ferrandiz et al., 2018).

There are intrinsically two aspects of BIM that need AEC-FM educators' and researchers' attention. The first, from an instrumentalist world view (Feenberg, 2001, 2017; Heidegger, 1977), which is generally acknowledged and predominantly studied is that AEC-FM graduates would understand the use and application of BIM in the industry (Puolitaival \& Forsythe, 2016; Ramalingam, 2018; Solnosky, 2018; Wu \& Luo, 2016) - this is taken to be a short- term industry need where "teaching BIM is prioritized" (Witt \& Kähkönen, 2019). The second aspect, based on substantivism, is the use of BIM as a platform or medium for AEC-FM education. Moreover, and for both aspects, curriculum design and evaluation criteria have been reported to be major challenges especially in the face of multiple ways of embedding BIM into the AEC-FM curriculum in any educational institution with their unique context, policies and strategies (Sacks \& Pikas, 2013).

$\mathrm{BIM}$ for construction education (BfCE) is a term used in this study to refer to all efforts by academia in educating AEC-FM students both on how to use BIM and / or leveraging BIM to enhance learning. Earlier research by the authors has confirmed a number of existing cases of BfCE reported in the academic literature and suggests that these are dominated by architectural disciplines and that reports on construction management related courses are increasing with time. Only two literature reviews on general BIM education were found (Abdirad \& Dossick, 2016; Pikas et al., 2013) that focused on curriculum design frameworks. However, understanding the development

${ }^{\star}$ Corresponding author. E-mail: theophilus.olowa@taltech.ee 
process of BfCE model offerings is important for designing appropriate BfCE approaches in universities. Whereas previous studies have effectively reported developments in BIM education, none of them has attempted to conceptualise the patterns underlying the dispersed facts.

The scarcity of extant literature relating to the classification of approaches to BfCE is also notable. To our knowledge, there are only two studies that have reported on the categorisation of different models of BfCE offerings in higher education institutions (Solnosky \& Parfitt, 2015; Suwal \& Singh, 2018) and none on universities specifically. According to Solnosky and Parfitt (2015) "The number and types of methods for teaching and integrating BIM... into building related architectural engineering related curriculums... is varied due to its broad definition and based on the wide body of different building expertise." With this explanation, they came up with a categorisation that is based on number of disciplines involved, course design and number of institutions involved. Suwal and Singh (2018) base their categorisation solely on course design and number of disciplines involved. However, neither of these studies systematically define the human actions and interactions involved in their categorisations thereby giving explanations for their use. Both Solnosky and Parfitt (2015) and Suwal and Singh (2018) are already somewhat dated and, since more examples of BfCE now exist, a more rigorous attempt at categorisation is now feasible.

This study is an attempt to fill this gap by synthesising the evidence from the extant literature on BfCE cases to gain an understanding of existing BfCE implementation strategies in universities and develop a typology of BfCE approaches in AEC-FM disciplines as well as a conceptual framework to explain the drivers and processes associated with BfCE. This is a first step in addressing the wider research problem: how can BIM be leveraged to improve engineering education in AEC-FM disciplines?

A systematic search of the academic literature was carried out to identify peer-reviewed journal and conference papers on BIM education in higher education institutions (HEIs). Cases of BIM for construction education for AECFM students in universities reported in these papers were then identified and analysed. The literature search criteria and analysis process are described in Section 1. Section 2 presents the main findings from the analysis of the cases identified and these are discussed and interpreted in Section 3 where a typology of BfCE approaches and a conceptual framework for BfCE are derived before conclusions and implications for further research are drawn.

\section{Research methodology}

Systematic literature reviews are "rigorously designed and conducted literature reviews that aim to exhaustively search for, identify, and appraise the quality of and synthesize all the high-quality research evidence in order to answer a specific research question" (Phillips et al., 2018). This approach enables the comprehensive review of the extant literature within the scope of the research in a re- producible and rigorous manner and, moreover, the results of systematic literature reviews have been argued to be as valuable as those of any other evidence-based methodologies in educational interventions (Evans \& Benefield, 2001; Phillips et al., 2018). The methodology adopted for this research followed the recommendations of Gough (2007) for conducting systematic literature reviews as summarised under the following 9 process steps by Bearman et al. (2012): "(1) establishing the review question; (2) defining inclusion and exclusion criteria; (3) articulating the search strategy, including information sources; (4) screening the articles to see if they meet the inclusion and exclusion criteria; (5) reporting the results of the search strategy, usually through a flowchart; (6) extracting relevant data from included studies; (7) assessing the methodological quality or rigour of the included studies; (8) synthesising, either quantitatively or qualitatively, the collective evidence of the included studies; (9) drawing conclusions and communicating these findings in a manner which is relevant to readership".

Establishing the review question: The review question guiding the direction of this study was: What are the existing cases of BfCE in universities?

Defining inclusion and exclusion criteria: All academic publications relating to BfCE from any year and any country were included but only English language publications were considered. Academic publications refer to peer reviewed journal articles and conference proceedings that report on actual research on any aspect of BIM education in universities. Trade publications, and other non-academic sources and books were excluded on the grounds that the quality of their content could not be similarly assured (e.g. these could include promotional content).

Articulating the search strategy: An initial search was conducted on two online databases (ASCE journal and ASEE conference papers that were published in 2018) to identify the appropriate search terms. The Boolean phrase with the following search operators was used: ("Building Information Mode?1*" OR "BIM") AND ("Educat*" OR “Teach*” OR "Learn*”) AND ("Construction management" OR "Project Management" OR "Engineering Management") to locate relevant references. This was done reiteratively with the introduction of wildcard (? - e.g. Mode?ing) and truncation $\left({ }^{*}-\right.$ e.g. Model $\left.^{*}\right)$ search operators to exhaustively glean all relevant references. The following online databases were searched for relevant articles (i.e. articles containing the search terms which are generated automatically by the search engine): EBSCOhost Web; EBSCO eBooks Collection; ASCE Library; ASME Journals and Conference Proceedings; Cambridge Core; Emerald; ScienceDirect; Scopus (Elsevier); Web of Science (Clarivate Analytics). However, not all databases proved equally relevant and the articles returned are shown in Table 1.

Screening the articles: The articles returned from the search of databases were listed in order of relevance by the algorithms of the database search engines such that 
Table 1. Databases with breakdown of articles returned

\begin{tabular}{|l|c|c|}
\hline \multicolumn{1}{|c|}{ Databases } & $\begin{array}{c}\text { Articles returned } \\
\text { from search } \\
\text { expression }\end{array}$ & $\begin{array}{c}\text { Relevant articles } \\
\text { after screening }\end{array}$ \\
\hline EBSCOhost Web & $3,968^{\left({ }^{*}\right)}$ & 192 \\
\hline Science Direct & 269 & 12 \\
\hline ASCE Library & 1921 & 211 \\
\hline Emerald Insight & 237 & 15 \\
\hline Scopus & $2558^{(*)}$ & 118 \\
\hline Web of Science & 504 & 68 \\
\hline $\begin{array}{l}\text { Overall (with } \\
\text { duplicates removed) }\end{array}$ & N/A & 305 \\
\hline
\end{tabular}

the articles most aligned with the search string and filters were returned at the top of the list and those increasingly less aligned with the search terms appeared further down the list. The articles were screened using their titles and, where necessary, their abstracts were also read to establish their relevance to this enquiry. The Mendeley web plugin was used in conjunction with the Google Chrome browser to download the articles (as pdf files) into individual folders for each database for further analysis. All of the files from all the folders were then collated into a single folder to identify and eliminate duplicates using Mendeley reference management software which resulted in a total of 305 relevant BfCE articles. From the total of 305 articles found, forty-four (44) articles were found to report actual cases (using action or case study research) of $\mathrm{BfCE}$ in AEC-FM in universities. These 44 cases were found to have adequately similar data so that a constant comparative analysis could be carried out.

Reporting the results of the search: Table 1 shows the results of the search strategy.

Note that the high number of returns from the EBSCOhost Web and Scopus databases were mostly irrelevant the screening process (going through each paper's title and, where necessary, abstract) was discontinued at return record \#600 (EBSCOhost Web) and record \#1100 (Scopus) after a full 50 records (listed according to relevance) in sequence had been found to be irrelevant. The results of the constant comparative analysis are reported in Section 2 and further discussed and interpreted in Section 3.

Data Extraction from included studies: Data extraction followed a qualitative approach which was achieved with the aid of NVivo Plus (v.12) software. The research question guided the mining of data, and contents were probed accordingly throughout the extraction process for comparative content analysis of the cases. Themes and patterns were coded as they emerged. The analysis also considered some quantitative metrics to clearly present trends of all the considered factors that impact on BfCE in this study. Therefore, this study adopted a mixed method approach in the collection, organisation, analysis of data and presentation of results (the results are presented in Section 2).

Assessing the methodological quality or rigour of the included studies: The quality and rigour of the studies in- cluded was premised on their appearance in peer-reviewed journal and conference proceedings publications and all included studies were considered to be equally valid.

Synthesizing the evidence: A Grounded Theory (GT) approach was adopted for synthesis. Specifically, a metaanalysis and content comparison of cases were carried out using the Straussian Theory Model (STM). The data from relevant extant textual cases were coded following a constant comparative analysis. The identified themes were linked into concepts, from concepts to sub-categories and subsequently into categories to explore the conditions, context, consequences, and strategies (actions and interactions) as well as the relationships between them as suggested by Corbin and Strauss (1990), Creswell (2012). On this basis, a typology and conceptual framework for BfCE in universities were derived (as presented in Section 3).

Grounded Theory (GT) is a rigorous systematic inductive approach to understanding social process(es) by analyzing any form of data and allowing the analyst to freely come up with substantive theory that is both compatible and consistent with empirical observation without the restriction of precepts of any existing theory about a phenomenon (Urquhart, 1997). Since this study is aimed at understanding the BfCE phenomenon on the basis of extant cases and in the absence of existing theory, GT provides a convenient approach for doing this. Specifically, the Straussian Theory Model (STM) of GT was adopted as a prescriptive methodology for the meta-analysis, content comparison and theory generation from the cases.

Figure 1 illustrates the STM as presented by Creswell (2012). In generating substantive theory using GT, Creswell (2012) suggests that emphasis should be on process rather than consequences. A process in GT research, according to Strauss and Corbin (1998), "is a sequence of actions and interactions among people and events pertaining to a topic". In adopting STM, BfCE was thus considered as a social process and the analysis proceeded according to three prescribed steps (Strauss \& Corbin, 1998; Creswell, 2012):

1. Open coding - formation of initial categories of information regarding the phenomenon;

2. Axial coding - identifying a core category and determining the relationships between that and the other identified categories (see Figure 1);

3. Selective coding - theory development in attempting to explain the relationships determined above.

Drawing conclusions: The 9th step in the systematic literature review process described by Bearman et al. (2012) relates to drawing conclusions from the outcomes of the research. Our conclusions are presented in the final section.

\section{Results}

\subsection{Summary of BfCE cases}

Table 2 shows the summary of all the BfCE cases in this study categorized according to the type of disciplines engaged, what was taught and how they were taught. 


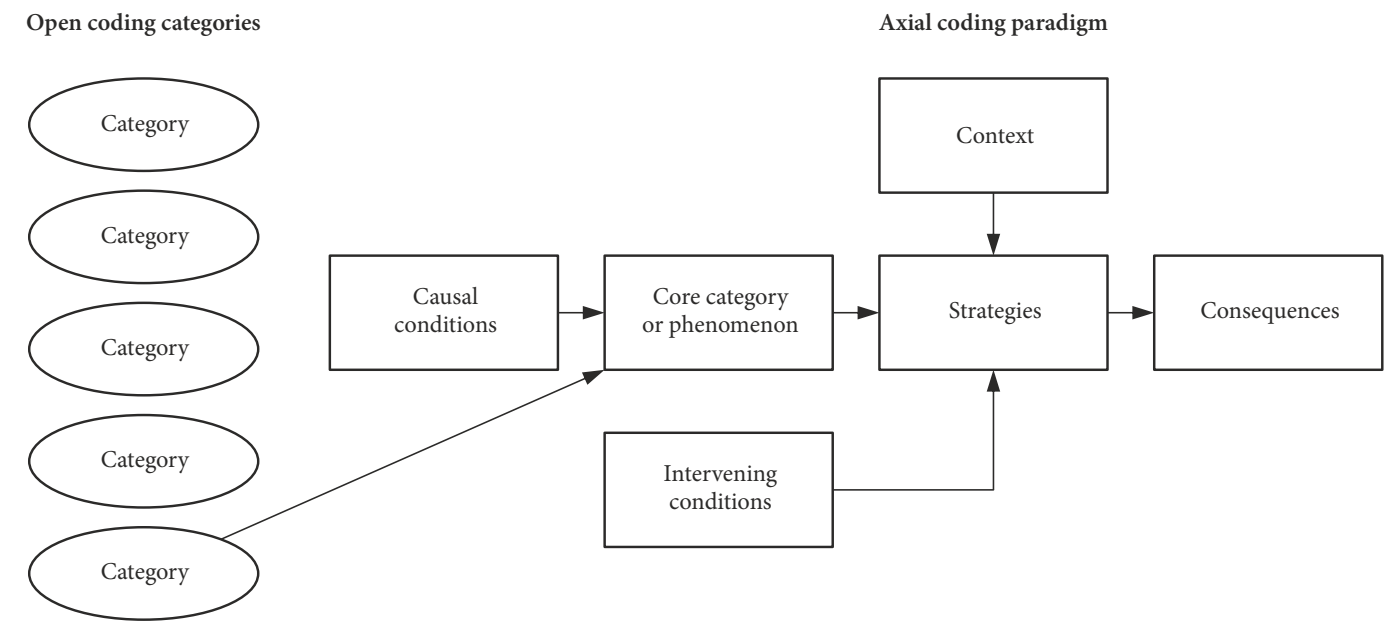

Figure 1. Grounded Theory coding from open coding to the axial coding paradigm (Creswell, 2012)

Table 2. Summary table of BfCE cases

\begin{tabular}{|c|c|c|c|c|}
\hline Discipline & \# cases & Teaching basis* & Learning foci & Delivery \\
\hline Architecture & 12 & $\begin{array}{l}\text { project (5) } \\
\text { case (3) } \\
\text { problem (5) }\end{array}$ & $\begin{array}{l}\text { capstone (course integration); design } \\
\text { integration; building materials, } \\
\text { technology and systems; construction; } \\
\text { sustainability }\end{array}$ & $\begin{array}{l}\text { Undergraduate, postgraduate or } \\
\text { both combined. Single topic within } \\
\text { course to full course. Less than } \\
1-10 \text { semesters. Single or multiple } \\
\text { institutions }\end{array}$ \\
\hline Construction & 12 & $\begin{array}{l}\text { project }(3) \\
\text { case }(6) \\
\text { problem }(5)\end{array}$ & \begin{tabular}{|l|} 
capstone (course integration); IT for \\
construction; construction principles \\
and practice; building technology \\
and systems; energy simulation; BIM \\
process and applications; collaboration
\end{tabular} & $\begin{array}{l}\text { Undergraduate, postgraduate } \\
\text { or both combined. Full course. } \\
1-8 \text { semesters. Single institutions }\end{array}$ \\
\hline Civil and structural & 4 & $\begin{array}{l}\text { project }(0) \\
\text { case }(0) \\
\text { problem }(3)\end{array}$ & $\begin{array}{l}\text { BIM awareness; BIM terminology } \\
\text { and process, applications and tools; } \\
\text { visualisation }\end{array}$ & $\begin{array}{l}\text { Undergraduate or postgraduate. } \\
\text { Full course. } 1 \text { semester. Single } \\
\text { institutions. }\end{array}$ \\
\hline $\begin{array}{l}\text { Other (individual) } \\
\text { disciplines } \\
\text { (Building and Real } \\
\text { Estate; Geoinformatics; } \\
\text { undefined) }\end{array}$ & 3 & $\begin{array}{l}\text { project }(1) \\
\text { case }(1) \\
\text { problem }(0)\end{array}$ & $\begin{array}{l}\text { Development of CAD in construction. } \\
\text { BIM awareness; BIM applications and } \\
\text { tools; BIM for FM; BIM futures }\end{array}$ & $\begin{array}{l}\text { Undergraduate. Full course. } \\
1 \text { semester. Single institution }\end{array}$ \\
\hline $\begin{array}{l}\text { Combinations of }(2-8) \\
\text { disciplines }\end{array}$ & 13 & $\begin{array}{l}\text { project }(3) \\
\text { case }(4) \\
\text { problem }(4)\end{array}$ & $\begin{array}{l}\text { Capstone (course integration - for } \\
\text { solar decathlon competition); BIM } \\
\text { applications; interoperability }\end{array}$ & $\begin{array}{l}\text { Undergraduate, postgraduate } \\
\text { or both combined. Full course. } \\
1-6 \text { semesters. Single or multiple } \\
\text { institutions. }\end{array}$ \\
\hline
\end{tabular}

Note: ${ }^{\star}$ Some cases contain more than 1 type or none at all.

Of the 44 cases identified, the majority (34) were from the USA, 4 were from China, 2 from the UAE and the remainder from other countries across the globe contributing only 1 case each to the sample.

\subsection{Disciplines}

Table 2 shows the spectrum of disciplines engaged in the BfCE studies which were explicitly or implicitly extracted from the cases and how they are combined in some cases. 28 of the cases involved just a single discipline. Architecture and Construction were the dominant disciplines with 12 cases each. The rest are combinations of different disciplines with two being the least and the greatest number of combined disciplines in a single case was found to be 8 (see Bozoglu, 2016; Chiuini et al., 2013). It was, how- ever, not possible to get the same detail from one of the cases due to its non-specificity and lack of any indication to implicitly deduce the discipline to which it referred. Nevertheless, the diversity of possibilities in which BfCE is executed among AEC-FM disciplines in universities was apparent - and this even extends beyond solely AEC-FM disciplines in one of the cases to Business and Communication disciplines.

\subsection{Teaching basis}

Expanding the ideas of Mills and Treagust (2003) regarding project- and problem-based learning, we have included a third category for the purpose of this study, which is case-based learning as defined by Barison and Santos (2018). The dissenting ideas about project-based 
and problem-based learning have prompted the publication of many articles, for example, Mills and Treagust (2003) and Helle et al. (2006). Helle et al. (2006) in their exploration of project-based learning (PrBL) in education highlight the general characteristics of PrBL as: "(1) [projects] involve the solution of a problem; often, though not necessarily, set by the student himself [or herself]; (2) they involve initiative by the student or group of students, and necessitate a variety of educational activities; (3) they commonly result in an end product (e.g., thesis, report, design plans, computer programme and model); (4) work often goes on for a considerable length of time; (5) teaching staff are involved in an advisory, rather than authoritarian, role at any or all of the stages - initiation, conduct and conclusion".

Although these general characteristics do not specifically refer to projects as being real-life, in the context of BIM and AEC-FM disciplines, projects generally refer to construction and their ancillary works which are always real-life (Mills \& Treagust, 2003). While problem-based learning (PBL) was not within the exploratory scope of Helle et al. (2006) they, however, argued that some common features between PrBL and PBL include the presence of problem orientation, i.e. learning is propagated through the formation of a problem; and collaboration and cooperation among group members. Furthermore, they suggest that the difference is in the way knowledge is applied to the problem formed. In PBL this typically involves the application of already acquired knowledge, while PrBL requires the acquisition of new knowledge. We found, in the literature reviewed, that the terms PrBL, PBL and also case-based learning were used loosely and interchangeably in many of the articles that we analysed. Therefore, to avoid misrepresentation, we have defined the concepts of PrBL, PBL and CBL as used for the classification of articles in this study. Project-based learning is centred around real-life projects where students/learners take active roles in the execution of the projects or collaborate closely with the professionals on the project. Case-based learning is centred around completed real life projects where students/learners have no active roles to perform in the execution of the project but have access to some or all the professionals on such projects to obtain partial or full information on the project (Barison \& Santos, 2018). In problem-based learning, the learners are totally dissociated from both the project and the professionals on the project. Problems, having semblance of real-life based on the experience of the educator, are usually built on hypothetical cases for learners to solve.

Table 2 illustrates that all 3 of these approaches have been popular in BfCE with almost all identified cases employing 1 or more of them as a basis for teaching. The first case reported on BfCE had no indication of the teaching basis adopted in the study, references to the basis of teaching started emerging a year after the first case was reported. The reporting of project-based cases stopped in 2015 with the highest number reported in 2013. There is no apparent preference for either problem-based or casebased approaches to BfCE.

\subsection{Learning foci}

Learning foci in the cases ranged from BIM awareness, applications, tools and processes to BIM-based course integration in capstone projects and the subject areas spanned the whole life of constructed assets. The application of theoretical topics leading to practical design and/or construction documentation, especially in capstone projects, were prominent. In addition, dissertation and thesis writing on BIM by Masters and PhD students were also observed to be of interest to some authors.

\subsection{Delivery}

The cases showed a variety of delivery possibilities in relation to:

- whether the BfCE intervention was a topic within a course or a full course;

- the level of students - undergraduate and postgraduate as well as combinations of both;

- the length of courses - from less than 1 to a full 10 semesters;

- the number of institutions involved in the delivery.

\subsection{Approaches}

10 specific types of approaches were identified from the literature and these are:

Approach Type 1: Undergraduate Mono-discipline (Topic) - in a single institution: In this category, BfCE only involves undergraduates who are in the same institution and share the same discipline. This approach is particularly favoured by faculties that practice BIM-enabled education. In this approach, AEC-FM concepts such as cashflow, estimating, structures, etc., which go beyond emphasising the digitalisation of the construction industry, are taught at topical levels. In most cases, there is no space in the curriculum for faculties to have a full-blown course for BfCE. Furthermore, this method of BfCE does not require any prerequisite course(s), mentoring, involvement of alumni nor guest speakers for its implementation. An example of a case with this approach is Sharag-Eldin and Nawari (2010), where the teaching and learning also happened in both traditional classroom and a studio setting.

Approach Type 2: Undergraduate Mono-discipline (Course) - in a single institution: This approach, though similar to the first type, is different in that the combined condition under which this is practiced allows extended time for such teaching and learning which culminates in a dedicated course for BfCE. This approach allows for either training students on basic engineering concepts or how to use BIM software. This approach can include the participation of guest lecturers and the requirement that students have already completed prerequisite courses. Teaching and learning may be carried out in a combined environment i.e. both traditional classroom and laboratory/studio setting (e.g. Kim, 2014).

Approach Type 3: Undergraduate Multidisciplinary (Course) - in a single institution: This approach is widely 
used and encompasses multiple disciplines, but all located in the same institution. Properties of this approach with varied nuances include prerequisite courses, combined environments, guest lecturers. Example cases include Comiskey et al. (2017), Solnosky and Parfitt (2015), Wong et al. (2011), Bozoglu (2016), Zhang et al. (2017, 2018), Pikas et al. (2013), Monson and Dossick (2014), Jin et al. (2018), Nawari et al. (2014).

Approach Type 4: Undergraduate Multidisciplinary (Course) - in multiple institutions: This refers to the extension of BfCE beyond a single institution by collaborating with other institutions. The maximum combination of institutions recorded in this study is two. This approach is undertaken where there is adequate time (usually at least a semester) to carry out the teaching and learning with the support/mandate of participating institutions. Of paramount importance for such arrangements is the availability of complementary technology such as an online collaboration platform and ability for time coordination in cases where the institutions have different time zones. This approach may be adopted in cases where institutions wish to leverage individual strengths in areas like core discipline focus and availability of technical resources. Properties of this approach include courses being carried out in a combined environment with some prerequisite knowledge required by the students and facilitated by guest lecturers (e.g. Comiskey et al., 2017).

Approach Type 5: Postgraduate Mono-discipline (Course) - in a single institution: This involves teaching and learning of BfCE activities among master's students and sometimes doctoral students. However, the involvement of the doctoral students is usually for facilitating i.e. they are involved because their supervisors or departmental heads are teaching the subject and are consequently needed in BfCE role playing. The conditions which impact the choice of this approach include the organisational structure of the institution in that the faculty possesses the authority, the skill in BIM software application with the time and resources required for the implementation of this approach. The examples of this approach involved learning taking place in a combined environment, with or without requiring the completion of prerequisite courses and with or without the participation of guest lecturers and/or industry experts. Cases included Hijazi et al. (2018), Wang and Leite (2014), Suwal and Singh (2018), Sampaio (2015), Pikas et al. (2013), Nassar (2012).

Approach Type 6: Postgraduate multidisciplinary (Course) - in a single institution: The notable feature of this approach type is the diversity of the students involved. This is made possible by the presence of other, complementary disciplines within the institution where the study is conducted. It is worth mentioning that the availability of resources such as high-end computers and software is important. Variants include learning in a combined environment or in a studio environment only, with or without participation of guest lecturers and, typically, without prerequisites. Example cases include Charlesraj et al. (2015), Bozoglu (2016), Pikas et al. (2013), Shanbari et al. (2016).
Approach Type 7: Mixed Level Single Discipline (Course) - in a single institution: In this category, teaching and learning take place among students of the same discipline within the same institution but who are at 2 or more different levels in their studies. For example, year 3 and year 4 students might be taught at the same time with the option of deferring the course to year 4 by year 3 students. This approach is typically carried out in a combined learning environment and variants include: the requirement for prerequisite courses, participation of guest lecturers and industry mentors, incorporation as a capstone project. Example cases include Wu and Hyatt (2016), Lewis et al. (2015), Wu and Luo (2016). Time and resources availability are important factors in implementing this type of approach as these can be beyond faculty capacities and thus reliant on national or institutional mandates to encourage this approach.

Approach Type 8: Mixed Level Multidisciplinary (Course) - in single institutions: This categorisation relates to the engagement of more than one discipline in different levels of studies but in the same institution. This arrangement is particularly practiced where the topic or course involved is either an elective or core course that is taken by different levels of students from different disciplines. To an even greater extent than approach Type 7, this approach relies on the organisational structure allowing for proper coordination and collaboration and institutional/national mandates for encouraging them. These approaches are typically carried out in combined learning environments either with or without prerequisites and mentors. Example cases include Chiuini et al. (2013), Rassati et al. (2010), Leite (2016).

Approach Type 9: Mixed Level Multidisciplinary (Course) - in multiple institutions: faculties and students from different institutions are involved in the teaching and learning of BfCE activities respectively. This approach usually take place at capstone level, where participants from both institutions combine their efforts to complement disciplines that are not available in both institutions. Additionally, this approach is suitable for the demonstration and teaching of the collaborative aspects of non-collocated participants in real or simulated construction projects. The amount of time allocated for such studies is usually not less than a semester due to the range of technical and academic activities involved. Only one example case of this approach was uncovered in the study (Becerik-Gerber et al., 2012) and this was conducted in a combined learning environment, involved the participation of software/ industry mentors and required no prerequisite courses. The availability of suitable software and hardware to facilitate self-learning and communication was particularly important.

Approach Type 10: Mixed-MULTIPLE Levels Multidisciplinary (Course) - in a single institution: This approach involves the collaboration of different levels of students from one discipline with another set of students at different levels from another discipline but all being enrolled 
at the same institution. This is an expansion of approach Type 8 where the students from each discipline involved are usually representative of only one level, but which may be different to each other. Here, there is a lot of vertical and horizontal integration in the composition of the student group and this allows for simulating differential knowledge levels within an organisation and the diversity of focus areas while encouraging collaboration and learning. Practicing this approach requires considerable time coordination among levels and departments, access to training software and other technical resources and some level of software skill which could be compensated for by engaging industry or software mentors (see Zhao et al., 2015).

\section{Discussion and interpretation of results}

\subsection{Open Coding}

Open coding signifies the first level of data analysis. According to Corbin and Strauss (1990), during open coding, data are weighed against one another for the purpose of identifying what they have or do not have in common based on events/actions/interactions surrounding them. Categories and subcategories are formed when common concepts emerge that have been labelled a priori. Open coding was carried out for all the cases through reading the texts line by line and using NVivo Plus (v.12) to parse information for categorisation into themes and sub-themes after highlighting and extracting relevant indicators and incidents as codes. Further incidents and indicators that generally relate to the question of this study resulted in a total of 429-open codes that were subsequently parsed into 58-open code categories such as: causes of BfCE, advantages, disadvantages, the environment in which teaching and learning took place, teaching methods employed, stage of BIM education, delivery, learning foci, number of semesters for which the learning lasted; number of institutions combined in the cases, effects, limitations, challenges, etc.

\subsection{Axial Coding}

Axial coding involves identifying relationships among the properties and dimensions of the identified categories while relating them to the core phenomenon under study. The 58-open coding categories were rearranged to align with the given categories shown in the Axial Coding Paradigm of Figure 1, i.e. the causal conditions, core category or phenomenon, context, intervening conditions, strategies and consequences. These are expanded upon in turn below.

\subsubsection{Causal conditions}

The causal conditions include: leveraging BIM technology to educate students on designing, building and operating a net-zero energy prototype building culminating in capstone experience in some cases; understanding construction information management and storage platforms; perceived requirement by graduates to operate in a tech- nologically driven world of work; ability of new employees to use BIM technologies and using 'a' BIM platform as ' $a$ ' conduit for the integration of complementary innovations e.g. laser scanning, photogrammetry, building inspection/ surveillance and point cloud computing using unmanned drones. The causal conditions were understood, in a general sense, to be elements of the digitalisation of the construction industry.

\subsubsection{Core phenomenon}

BfCE was considered to be the core phenomenon for this study given its centrality to the whole process. In order to understand why construction educators engage in BfCE, varying indicators emerged that were grouped under this theme. From the Axial Coding Paradigm (ACP), this phenomenon is motivated by the causal conditions noted above. Faculties' specific responses take the form of different strategies or approaches to the implementation of $\mathrm{BfCE}$ and these are influenced by both context and intervening conditions. The strategy or approach adopted results in specific outputs or consequences.

\subsubsection{Context}

The contextual and intervening conditions governing the selection of specific strategies were considered in terms of factors at the macro, meso and micro scales. Macro conditions refer to international, national and community events that directly affect a study or institution to which the study is affiliated. Meso conditions relate to institutional factors and the micro level refers to sub-organisational and sub-institutional factors. Following the suggestions of Corbin and Strauss (1990), both macro and meso factors were regarded as contextual conditions whereas micro level factors were considered to be intervening conditions. Contextual conditions identified included:

Era: Era is a subtle factor and all the approaches are influenced by it as all the cases are in one way or another responsive to the 1987 launch of the BIM technology. Looking back to the launch of the first sets of commercially available BIM software in 1987 (Eastman et al., 2011; Quirk, 2019), and also giving consideration to technology shelf life of about 5 years, the time frame given for the implementation of key BIM guidelines in UK (Adamu \& Thorpe, 2016) and global effort by public sector on BIM adoption, BfCE only began in 2006-2010 and has since then gathered momentum.

National or institutional mandate: National or institutional mandate is one of the identified factors responsible for two things in the development of BfCE. First influence was how fast this motivated the faculty in starting albeit faster than they probably would have started. Secondly, is the breadth of engagement. This influence is pronounced owing to the ability of the department to involve more than one discipline in most cases.

Industry demand: The surge in industry demand for graduates who are knowledgeable and well-grounded in BIM technology and processes (Deniz, 2018) has in- 
creased the sensitivity of academia towards BfCE. The advent of BIM has brought with it new industry roles such as BIM coordinator, BIM manager, etc. Training of these employees is considered economical if approached and addressed through academes such as universities (Palomera-Arias, 2015; Palomera-Arias \& Liu, 2016). To meet industry demand, academia has in the past 5-6 years improved BIM awareness among university students and explored new didactics methodologies to use BIM in their teaching. However, faculties have been admonished not to focus teaching only on the present needs of the industry but on fostering well rounded graduates that would both be able to serve in the current industry and the industry of the future (Clarke, 2012; Underwood et al., 2019).

Environmental issues: Environmental issues such as sustainability, global warming, waste management, etc. have enjoyed better explication through BIM environments. Faculties have actively leveraged BIM capabilities e.g. visualisation, simulation, ability to organise data, etc. to both illustrate and teach the students about these issues.

Accreditation requirements: Accreditation bodies and their requirements have also impacted the level of BfCE development and delivery approaches. Formalising BfCE requirements is considered a forceful impetus in promoting BfCE in universities.

\subsubsection{Intervening conditions}

As noted above, intervening conditions were taken as referring to micro level factors. Intervening conditions identified from the cases included the following.

Resources: Resources refers to the assets that facilitate the delivery of BfCE. These include facilities such as classrooms, design/computer studios, etc. or more technical artefacts such as hardware and software. The presence (or absence) of these resources strongly influence faculties' approaches to BfCE as well as what is taught.

Time coordination: The amount of time available and its coordination is another factor influencing the BfCE approach adopted. The limited number of weeks in any academic calendar drives the prioritisation of what is to be taught within the available time. Time coordination is particularly important when collaboration between two or more disciplines and/or institutions are involved.

Skill level: Skill levels among both faculty and students influence the choice of didactical approaches. It was noted that a lack of skills discouraged or reduced the level of engagement with BfCE in some cases.

Organisational structure: Organisational structures affect the degree of autonomy that can be exercised by faculty members in modifying the curriculum and therefore have an influence on the ease with which BfCE can be incorporated into existing courses and curricula.

Guest lectures/External roles: The availability of guest lecturers and external role players including mentors, especially by alumni adds to the types of approach that may be adopted in any BfCE endeavour. These external forces may also impel faculty members to engage in $\mathrm{BfCE}$ when they share their industry experiences and express how important it is to have BIM-ready graduates.

\subsubsection{Strategies}

Strategies are the different approaches to BfCE that faculties adopt in response to causal conditions (the digitalisation of the construction industry) and which are influenced by both the context and by intervening conditions. These different ways and means of teaching different engineering concepts, processes, procedures, construction methodologies, etc. are reflected in the combinations apparent in Table 2, i.e. teaching basis, learning foci and delivery.

\subsection{Typology of BfCE approaches}

A typology of the different approaches to BfCE was derived by the authors and is presented in Table 3. Our analysis of the cases found that all the identified BfCE approaches can be conveniently described in terms of the level of delivery, whether it is mono- or multidisciplinary, the scope of the offering and whether one or more institutions are involved. The 44 cases involved 10 distinct types of BfCE approaches but further combinations (which were not found in the sample cases) are also potentially feasible.

\subsection{Consequences}

14 indicators relating to the consequences of different approaches, their advantages and disadvantages were identified. In addition, it was noted that the different approaches to BfCE also had effects that could be categorised at a higher level of abstraction as either meeting immediate or short-term industry needs in terms of producing BIMready graduates who can 'do BIM' or meeting long-term needs through the leveraging of BIM to create a collaborative and immersive educational environment for teaching and learning. Table 4 illustrates the identified consequences and how they relate to the different dimensions of the various $\mathrm{BfCE}$ approaches.

\subsection{Selective coding}

Selective coding is the final phase of the theory derivation process where an attempt to explain and synthesize the interactions between the different categories of the axial coding paradigm is made in order to derive an understanding of the BfCE processes. The authors propose a conceptual framework as shown in Figure 2.

Digitalization of the construction industry is driving changes in construction industry needs (both short-term needs - immediate skills requirements; and long-term needs - reorganisation of industry and ways of working) and in construction education. Construction education is, on the one hand, responding to these industry needs, e.g. through providing students with BIM awareness and skills, and, on the other hand, it is leveraging the opportunities that arise from the digitalization of the construction 
Table 3. Typology of BfCE approaches with examples

\begin{tabular}{|c|c|c|c|c|c|c|c|c|c|c|}
\hline \multicolumn{3}{|c|}{ Level } & \multicolumn{2}{|c|}{ Discipline } & \multicolumn{3}{|c|}{ Scope } & \multicolumn{2}{|c|}{ Institutions } & \multirow[b]{2}{*}{ Examples found in the literature } \\
\hline 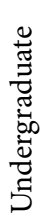 & 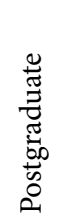 & 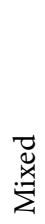 & 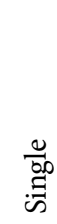 & $\frac{\stackrel{\ddot{Z}}{\Xi}}{\stackrel{\Xi}{\Xi}}$ & 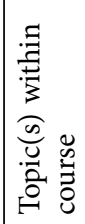 & 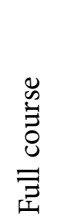 & 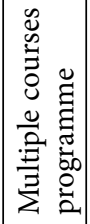 & 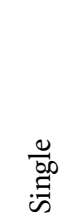 & 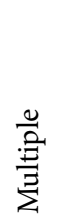 & \\
\hline$x$ & & & $x$ & & $x$ & & & $x$ & & Sharag-Eldin and Nawari (2010) \\
\hline$\times$ & & & $x$ & & & & $x$ & $x$ & & Kim (2014); Palomera-Arias (2015); Zhang et al. (2017) \\
\hline$x$ & & & $x$ & & & $\times$ & & $x$ & & $\begin{array}{l}\text { Pikas et al. (2013); Brioso et al. (2017); Wang and Leite (2014); } \\
\text { Dougherty and Kevin Parfitt (2013); Mathews (2013); Sands } \\
\text { et al. (2018); Shenton et al. (2014); Livingston (2008); Barham } \\
\text { et al. (2011); Palomera-Arias and Liu (2016); Shanbari et al. } \\
\text { (2016); Yi and Yun (2018) }\end{array}$ \\
\hline$\times$ & & & & $x$ & & & $x$ & $\times$ & & $\begin{array}{l}\text { Comiskey et al. (2017); Solnosky and Parfitt (2015); Wong et al. } \\
\text { (2011) }\end{array}$ \\
\hline$x$ & & & & $x$ & & $\times$ & & $x$ & & $\begin{array}{l}\text { Bozoglu (2016); Zhang et al. (2018); Pikas et al. (2013); Monson } \\
\text { and Dossick (2014); Jin et al. (2018); Nawari et al. (2014) }\end{array}$ \\
\hline$x$ & & & & $x$ & & & $x$ & & $x$ & Comiskey et al. (2017) \\
\hline & $x$ & & $x$ & & & & $x$ & $x$ & & Hijazi et al. (2018) \\
\hline & $x$ & & $x$ & & & $x$ & & $x$ & & $\begin{array}{l}\text { Wang and Leite (2014); Suwal and Singh (2018); Sampaio } \\
\text { (2015); Pikas et al. (2013); Nassar (2012) }\end{array}$ \\
\hline & $x$ & & & $x$ & & $x$ & & $x$ & & $\begin{array}{l}\text { Bozoglu (2016); Charlesraj et al. (2015); Pikas et al. (2013); } \\
\text { Shanbari et al. (2016) }\end{array}$ \\
\hline & & $\times$ & $\times$ & & & $x$ & & $\times$ & & Wu and Hyatt (2016); Lewis et al. (2015); Hu (2019) \\
\hline & & $x$ & & $\times$ & & $x$ & & $x$ & & Chiuini et al. (2013); Rassati et al. (2010); Leite (2016) \\
\hline & & $x$ & & $\times$ & & $x$ & & & $\times$ & Becerik-Gerber et al. (2012); Zhao et al. (2015) \\
\hline
\end{tabular}

Table 4. Consequences of adopting different BfCE approaches

\begin{tabular}{|c|c|c|c|c|c|c|c|c|c|c|c|}
\hline \multirow[b]{2}{*}{ ID\# } & \multirow[b]{2}{*}{ Consequences } & \multicolumn{3}{|l|}{ Level } & \multicolumn{2}{|c|}{ Disciplines } & \multicolumn{3}{|l|}{ Scope } & \multicolumn{2}{|c|}{ Institutions } \\
\hline & & 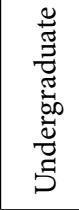 & 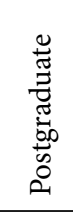 & 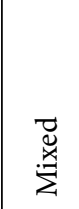 & $\begin{array}{l}\stackrel{0}{00} \\
\stackrel{5}{\leftrightarrows}\end{array}$ & $\frac{\frac{0}{2}}{\stackrel{3}{\Xi}}$ & 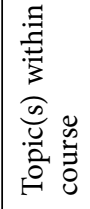 & 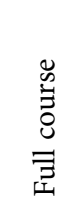 & 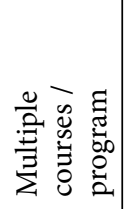 & $\frac{\mathscr{m}}{\mathscr{\infty}}$ & $\frac{\stackrel{0}{a}}{\stackrel{\Xi}{\Xi}}$ \\
\hline 1 & Need for approval from higher authorities & Low & Low & High & Low & High & Low & High & High & Low & High \\
\hline 2 & Time coordination difficulty & & & High & Lower & High & Low & & High & & Higher \\
\hline 3 & Previous BIM knowledge requirement & Low & Low & Low & Low & Low & Low & High & Higher & Low & Low \\
\hline 4 & Investment in hardware and software & & & & Low & High & Low & High & Higher & High & Higher \\
\hline 5 & Need for mentors & & & & & & Low & High & Higher & High & Higher \\
\hline 6 & Need for more than one faculty member & & & & Low & High & Low & High & Higher & High & Higher \\
\hline 7 & Suitability for teaching engineering concepts & & & & & & High & Low & Lower & & \\
\hline 8 & Requirement for BIM mandate & Low & Low & High & Low & High & Low & High & Higher & High & Higher \\
\hline 9 & Requirement for change in curriculum & & & & Low & High & Low & High & Higher & High & Higher \\
\hline 10 & Promotion of self-learning & & & & & & Low & High & Higher & & \\
\hline 11 & $\begin{array}{l}\text { Suitability for imparting a wide array of BIM } \\
\text { concepts and ideas }\end{array}$ & & & & Low & High & Low & High & Higher & High & Higher \\
\hline 12 & $\begin{array}{l}\text { Promotion of interdisciplinary learning / } \\
\text { communication / collaboration }\end{array}$ & Low & Low & High & Low & High & Low & High & Higher & High & Higher \\
\hline 13 & Time limitations & & & & & & High & Low & Lower & & \\
\hline 14 & Promotion of communication skills in students & & & & & & Low & High & Higher & & \\
\hline
\end{tabular}




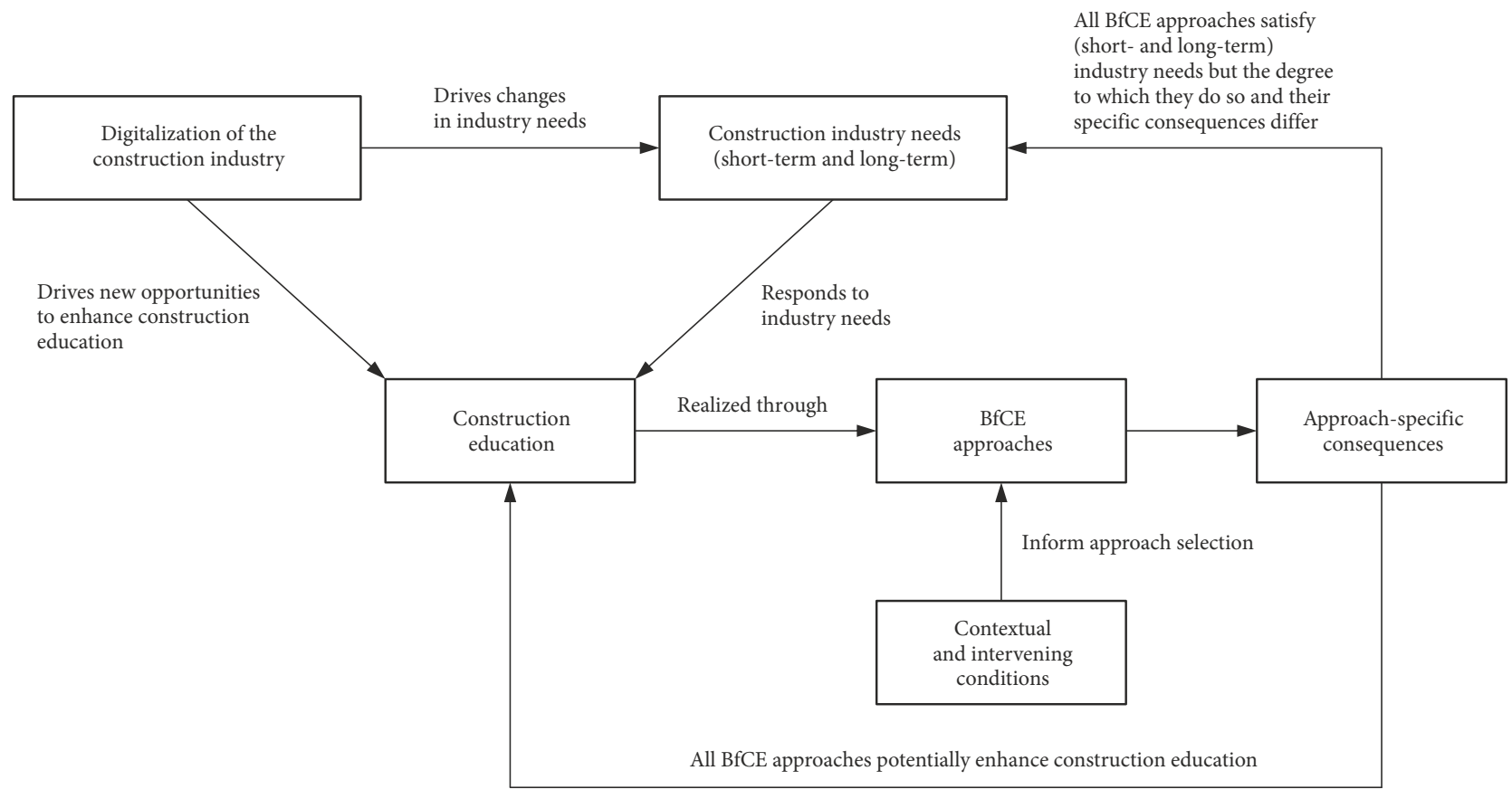

Figure 2. BfCE conceptual framework

industry to enhance construction education, e.g. opportunities for improved integration of curricula both within and between disciplines, closer correspondence of the teaching and industry environments through using real project data, etc. in the form of BIM-enabled education.

The changes to construction education are manifesting as different BfCE approaches which are enabled and constrained by contextual conditions (at the macro and meso levels) and intervening conditions (at the micro level) and these affect the selection of different BfCE approaches in any particular case.

All the different BfCE approaches are intended to satisfy the construction industry needs (both short-term needs and long-term needs) and to enhance construction education but they achieve these aims in differing degrees in accordance with their consequences.

\section{Conclusions}

This study set out to systematically synthesise extant cases of BIM implementation in universities' AEC-FM disciplines. A general awareness of the need to find and implement new strategies of educating professionals in the AEC-FM disciplines was found. This has been informed by recent changes in the digitalisation of the construction industry which are affecting the ways of working in the construction industry as well as giving rise to educational opportunities which could be useful in fostering graduates who would not just serve the short-term but also the longterm needs of the construction industry.

Universities are responding to these challenges with a diverse range of BfCE approaches which this study has recorded - going from a topical level to a whole curriculum level, with collaboration extending to multiple disci- plines involving many institutions at the same time. As wide as the level of engagement so is the diversity in the topics focused upon under different circumstances - from the elementary introduction of BIM to more advanced conceptual teaching in a virtual BIM environment. The formalisation of these approaches and the contextual and intervening conditions that support them can assist in decision making for BIM for construction education implementation in universities.

In this study, a Grounded Theory (GT) approach, specifically, a Straussian Theory Model (STM) has been adopted to identify and define the different BfCE approaches reported in the literature, the contextual and intervening conditions which give rise to them and their consequences and to develop a conceptual framework which sets out the relationships between these and the digitalisation of the construction industry. In addition, we have derived a descriptive typology that depicts all possible BfCE approaches.

The implications of this study for current practice include the formalisation of the processual activities of most (if not all) current BfCE approaches in AEC-FM education. Apart from course design, the number of disciplines and institutions involved in categorising the approaches as considered by previous authors, this study has taken account of the human elements underlining these approaches along with the causes, contextual and intervening conditions that influence approach choice and their attendant consequences. This can assist construction educators to understand and determine suitable approaches for either starting or extending their current teaching practice and to conceptualise new approaches that have yet to be tried and reported. 
With this understanding of $\mathrm{BfCE}$ approaches and processes, future studies will be geared towards the development and implementation of a pilot BfCE intervention within an action research framework. To enable this, we need to further investigate:

1. Specific university microenvironments including the one in which the pilot BfCE intervention will take place, their associated contextual and intervening conditions and how these shape BfCE approaches;

2. The mechanisms by which different BfCE approaches respond to perceived industry needs and how they are thought to enhance construction education.

This study is limited to peer reviewed journal articles and conference proceedings and searches conducted on only a few databases. We acknowledge that other approaches that may exist in other sources could have been omitted or unaccounted for in this study.

\section{Acknowledgements}

This research was supported by the Integrating Education with Consumer Behaviour relevant to Energy Efficiency and Climate Change at the Universities of Russia, Sri Lanka and Bangladesh (BECK) project co-funded by the Erasmus+ Programme of the European Union. The European Commission support for the production of this publication does not constitute an endorsement of the contents which reflects the views only of the authors, and the Commission cannot be held responsible for any use which may be made of the information contained therein.

\section{References}

Abdirad, H., \& Dossick, C. S. (2016). BIM curriculum design in architecture, engineering, and construction education: a systematic review. Journal of Information Technology in Construction (ITcon), 21, 250-271.

Adamu, Z. A., \& Thorpe, T. (2016). How universities are teaching BIM: A review and case study from the UK. Journal of Information Technology in Construction (ITcon), 21, 119-139.

Barham, W., Meadati, P., \& Irizarry, J. (2011). Enhancing student learning in structures courses with building information modeling. In Proceedings of Congress on Computing in Civil Engineering (pp. 850-857). American Society of Civil Engineers, Reston, VA. https://doi.org/10.1061/41182(416)105

Barison, M. B., \& Santos, E. T. (2018). Advances in BIM Education. In I. Mutis, R. Fruchter, \& C. C. Menassa (Eds.), Transforming engineering education (pp. 45-122). American Society of Civil Engineers, Reston, VA.

https://doi.org/10.1061/9780784414866.ch04

Bearman, M., Smith, C. D., Carbone, A., Slade, S., Baik, C., Hughes-Warrington, M., \& Neumann, D. L. (2012). Systematic review methodology in higher education. Higher Education Research and Development, 31(5), 625-640. https://doi.org/10.1080/07294360.2012.702735

Becerik-Gerber, B., Ku, K., \& Jazizadeh, F. (2012). BIM-enabled virtual and collaborative construction engineering and management. Journal of Professional Issues in Engineering Education \& Practice, 138(3), 234-245.

https://doi.org/10.1061/(ASCE)EI.1943-5541.0000098
Bozoglu, J. (2016). Collaboration and coordination learning modules for BIM education. Journal of Information Technology in Construction (ITcon), 21, 152-163.

Brioso, X., Murguia, D., \& Urbina, A. (2017). Comparing three scheduling methods using BIM models in the Last Planner System. Organization Technology and Management in Construction, 9(1), 1604-1614.

https://doi.org/10.1515/otmcj-2016-0024

Charlesraj, V. P. C., Sawhney, A., Singh, M. M., \& Sreekumar, A. (2015). BIM studio - An immersive curricular tool for construction project management education. In Proceedings of the 32nd International Symposium on Automation and Robotics in Construction and Mining: Connected to the Future. International Association for Automation and Robotics in Construction I.A.A.R.C, Oulu, Finland.

https://doi.org/10.22260/ISARC2015/0036

Chiuini, M., Grondzik, W., King, K., McGinley, M., \& Owens, J. (2013). Architect and engineer collaboration: The solar decathlon as a pedagogical opportunity. In AEI 2013 (pp. 216-225). American Society of Civil Engineers, Reston, VA. https://doi.org/10.1061/9780784412909.021

Clarke, B. (2012). The 2011 James Forrest lecture - engineering education - a historical perspective of the future. Civil Engineering and Environmental Systems, 29(3), 191-212. https://doi.org/10.1080/10286608.2012.710612

Comiskey, D., McKane, M., Jaffrey, A., Wilson, P., \& Mordue, S. (2017). An analysis of data sharing platforms in multidisciplinary education. Architectural Engineering and Design Management, 13(4), 244-261.

https://doi.org/10.1080/17452007.2017.1306483

Corbin, J. M., \& Strauss, A. (1990). Grounded theory research: Procedures, canons, and evaluative criteria. Qualitative Sociology, 13(1), 3-21. https://doi.org/10.1007/BF00988593

Creswell, J. W. (2012). Educational research Planning, conducting, and evaluating quantitative and qualitative research (4th ed.). Pearson.

Deniz, G. O. (2018). Emerging cad and bim trends in the AEC education: An analysis from students' perspective. Journal of Information Technology in Construction (ITcon), 23, 138-156.

Dougherty, J. U., \& Kevin Parfitt, M. (2013). Student and practitioner collaboration in an online knowledge community: Best practices from a capstone course implementation. Journal of Architectural Engineering, 19(1), 12-20.

https://doi.org/10.1061/(ASCE)AE.1943-5568.0000100

Du, J., Zou, Z., Shi, Y., \& Zhao, D. (2017). Simultaneous data exchange between BIM and VR for collaborative decision making. In ASCE International Workshop on Computing in Civil Engineering 2017. Seattle, Washington, USA.

https://doi.org/10.1061/9780784480830.001

Eastman, C., Teicholz, P., Sacks, R., \& Liston, K. (2011). BIM handbook: A guide to building information modeling for owners, managers, designers, engineers and contractors. John Wiley \& Sons, Inc.

Evans, J., \& Benefield, P. (2001). Systematic reviews of educational research: Does the medical model fit? British Educational Research Journal, 27(5), 527-541. https://doi.org/10.1080/01411920120095717

Feenberg, A. (2001). Questioning technology (2nd ed.). Taylor \& Francis.

Feenberg, A. (2017). Critical theory of technology and STS. Thesis Eleven, 138(1), 3-12.

https://doi.org/10.1177/0725513616689388 
Ferrandiz, J., Banawi, A., \& Peña, E. (2018). Evaluating the benefits of introducing "BIM" based on Revit in construction courses, without changing the course schedule. Universal Access in the Information Society, 17(3), 491-501.

https://doi.org/10.1007/s10209-017-0558-4

Gough, D. (2007). Weight of evidence: A framework for the appraisal of the quality and relevance of evidence. Applied and Practice-Based Research, 22(2), 213-228. https://doi.org/10.1080/02671520701296189

Helle, L., Tynjälä, P., \& Olkinuora, E. (2006). Project-based learning in post-secondary education - Theory, practice and rubber sling shots. Higher Education, 51(2), 287-314. https://doi.org/10.1007/s10734-004-6386-5

Heidegger, M. (1977). The question concerning technology and other essays. Harper \& Row, Publishers, Inc.

Hijazi, I., Donaubauer, A., \& Kolbe, T. (2018). BIM-GIS integration as dedicated and independent course for geoinformatics students: Merits, challenges, and ways forward. ISPRS International Journal of Geo-Information, 7(8), 319.

https://doi.org/10.3390/ijgi7080319

$\mathrm{Hu}, \mathrm{M}$. (2019). BIM-enabled pedagogy approach: Using BIM as an instructional tool in technology courses. Journal of Professional Issues in Engineering Education and Practice, 145(1), 05018017-1-05018017-05018019.

https://doi.org/10.1061/(ASCE)EI.1943-5541.0000398

Hwang, S., \& Safa, M. (2017). Learning advanced decision-making techniques and technologies through a collaborative project. In ASCE International Workshop on Computing in Civil Engineering 2017. Seattle, Washington, USA. https://doi.org/10.1061/9780784480830.005

Jin, R., Yang, T., Piroozfar, P., Kang, B.-G., Wanatowski, D., Hancock, C. M., \& Tang, L. (2018). Project-based pedagogy in interdisciplinary building design adopting BIM. Engineering, Construction and Architectural Management, 25(10), 13761397. https://doi.org/10.1108/ECAM-07-2017-0119

Kim, J. J. (2014, June). Effectiveness of green-BIM teaching method in construction education curriculum. Paper presented at 2014 ASEE Annual Conference \& Exposition, Indianapolis, Indiana.

Leite, F. (2016). Project-based learning in a building information modeling for construction management course. Journal of Information Technology in Construction (ITcon), 21, 164-176.

Lewis, A. M., Valdes-Vasquez, R., Clevenger, C., \& Shealy, T. (2015). BIM energy modeling: Case study of a teaching module for sustainable design and construction courses. Journal of Professional Issues in Engineering Education and Practice, 141(2), C5014005.

https://doi.org/10.1061/(ASCE)EI.1943-5541.0000230

Livingston, C. (2008). From CAD to BIM: Constructing opportunities in architectural education. In Architectural Engineering Conference (AEI) 2008. Denver, Colorado, USA. https://doi.org/10.1061/41002(328)5

Mathews, M. (2013). BIM collaboration in student architectural technologist learning. In M. Mathews (Ed.), Architectural technology: Research \& practice. Wiley.

https://doi.org/10.1002/9781118292365.ch5a

Mills, J. E., \& Treagust, D. (2003). Engineering education, is problem-based or project-based learning the answer. Australasian Journal of Engineering Education, 3(2), 2-16.

Monson, C., \& Dossick, C. S. (2014). Knowledge transfer with technology: Interdisciplinary team experiences in design and construction education. In 2014 International Conference on Computing in Civil and Building Engineering (pp. 2184-2191). Orlando, Florida, USA.

https://doi.org/10.1061/9780784413616.271
Nassar, K. (2012). Assessing building information modeling estimating techniques using data from the classroom. Journal of Professional Issues in Engineering Education and Practice, 138(3), 171-180.

https://doi.org/10.1061/(ASCE)EI.1943-5541.0000101

Nawari, N. O., Chichugova, T., Mansoor, S., \& Delfin, L. (2014). BIM in structural design education. In 2014 International Conference on Computing in Civil and Building Engineering (pp. 2143-2150). Orlando, Florida, USA.

https://doi.org/10.1061/9780784413616.266

Palomera-Arias, R. (2015, October). Building information modeling laboratory exercises in a construction science and management building systems course. In 2015 IEEE Frontiers in Education Conference (FIE). IEEE.

https://doi.org/10.1109/FIE.2015.7344058

Palomera-Arias, R., \& Liu, R. (2016). BIM laboratory exercises for a MEP systems course in a construction science and management program. Journal of Information Technology in Construction (ITcon), 21, 188-203.

Phillips, M., Van Epps, A. S., Johnson, N. E., \& Zwicky, D. A. (2018). Effective methods of engineering information literacy: Initial steps of a systematic literature review and observations about the literature. In ASEE Annual Conference and Exposition. Salt Lake City, UT, USA. https://doi.org/10.1016/j.acalib.2018.10.006

Pikas, E., Sacks, R., Hazzan, O. (2013). Building information modeling education for construction engineering and management. II: Procedures and implementation case study. Journal of Construction Engineering and Management, 139(11), 5013002 .

https://doi.org/10.1061/(ASCE)CO.1943-7862.0000765

Puolitaival, T., \& Forsythe, P. (2016). Practical challenges of BIM education. Structural Survey, 34(4/5), 351-366.

https://doi.org/10.1108/SS-12-2015-0053

Quirk, V. (2019). A brief history of BIM. Arch Daily. http://www. archdaily.com/302490/a-brief-history-of-bim

Ramalingam, S. (2018, July). Mapping of BIM process for teaching Lean. In 26th Annual Conference of the International Group for Lean Construction. Chennai, India. https://doi.org/10.24928/2018/0258

Rassati, G. A., Baseheart, T. M., \& Stedman, B. (2010). An interdisciplinary capstone experience using BIM. In Structures Congress 2010 (pp. 1689-1698). Orlando, Florida, USA. https://doi.org/10.1061/41130(369)154

Sacks, R., \& Pikas, E. (2013). Building information modeling education for construction engineering and management. I: Industry requirements, state of the art, and gap analysis. Journal of Construction Engineering and Management, 139(11), 04013016.

https://doi.org/10.1061/(ASCE)CO.1943-7862.0000759

Sampaio, A. Z. (2015). The introduction of the BIM concept in civil engineering curriculum. International Journal of Engineering Education, 31(1), 302-315.

Sands, K. S., Fiori, C. M., \& Suh, M. J. (2018). Beyond BIM: The evolution of an IT for construction course. In Construction Research Congress 2018 (pp. 54-64). New Orleans, Louisiana, USA. https://doi.org/10.1061/9780784481301.006

Shanbari, H. A., Blinn, N. M., \& Issa, R. R. (2016). Laser scanning technology and BIM in construction management education. Journal of Information Technology in Construction (ITcon), 21, 204-217.

Sharag-Eldin, A., \& Nawari, N. O. (2010). BIM in AEC education. In Structures Congress 2010 (pp. 1676-1688). Orlando, Florida, USA. https://doi.org/10.1061/41130(369)153 
Shenton III, H. W., Conte, P. R., Bonzella, J., Shenton, III, H. W., Conte, P. R., \& Bonzella, J. (2014). A first course in BIM for civil engineering majors. In Structures Congress 2014 (pp. 1097-1105). Boston, Massachusetts, USA. https://doi.org/10.1061/9780784413357.098

Solnosky, R. L. (2018). Opportunities for BIM to enhance structural engineering curricula. In Structures Conference 2018 (pp. 522-532). Fort Worth, Texas, USA. https://doi.org/10.1061/9780784481349.050

Solnosky, R. L., \& Parfitt, M. K. (2015). A curriculum approach to deploying BIM in architectural engineering. In AEI 2015 (pp. 651-662). Milwaukee, Wisconsin, USA. https://doi.org/10.1061/9780784479070.057

Strauss, A. L., \& Corbin, J. M. (1998). Basics of qualitative research: techniques and procedures for developing grounded theory. Sage Publications.

Suwal, S., \& Singh, V. (2018). Assessing students' sentiments towards the use of a Building Information Modelling (BIM) learning platform in a construction project management course. European Journal of Engineering Education, 43(4), 492-506. https://doi.org/10.1080/03043797.2017.1287667

Tranquillo, J., \& Kline, W. A., \& Hixson, C. (2018, June). Studentcreated canvases as a way to inform decision-making in a capstone design sequence. Paper presented at 2018 ASEE Annual Conference \& Exposition. Salt Lake City, Utah, USA.

Underwood, J., Khosrowshahi, F., Pittard, S., Greenwood, D., \& Platts, T. (2019). Embedding Building Information Modelling (BIM) within the taught curriculum: Supporting BIM implementation and adoption through the development of learning outcomes within the UK academic context for built environment programmes. The Higher Education Academy.

https://www.heacademy.ac.uk/system/files/bim_june2013.pdf

Urquhart, C. (1997). Exploring analyst-client communication: Using grounded theory techniques to investigate interaction in informal requirements gathering. In A. S. Lee, J. Liebenau, \& J. I. DeGross (Eds.), Information systems and qualitative research (pp. 149-181). Springer. https://doi.org/10.1007/978-0-387-35309-8_10

Wang, L., \& Leite, F. (2014). Process-oriented approach of teaching building information modeling in construction management. Journal of Professional Issues in Engineering Education and Practice, 140(4), 04014004.

https://doi.org/10.1061/(ASCE)EI.1943-5541.0000203

Witt, E., \& Kähkönen, K. (2019). BIM-enabled education: a systematic literature review. In 10th Nordic Conference on Construction Economics and Organization (Emerald Reach Proceedings Series), 2, 271-279.

https://doi.org/10.1108/S2516-285320190000002042

Wong, K. A., Wong, K. F., \& Nadeem, A. (2011). Building information modelling for tertiary construction education in Hong Kong. Journal of Information Technology in Construction (ITcon), 16, 467-476.

Wu, W., \& Hyatt, B. (2016). Experiential and project-based learning in BIM for sustainable living with tiny solar houses. Procedia Engineering, 145, 579-586. https://doi.org/10.1016/j.proeng.2016.04.047

Wu, W., \& Luo, Y. (2016). Pedagogy and assessment of student learning in BIM and sustainable design and construction. Journal of Information Technology in Construction (ITcon), $21,218-232$.
Yi, T., \& Yun, S. (2018, October). BIM (Building Information Modeling) education program in KSA: A case study of BIM program at Prince Sultan University. In International Conference on Civil and Environmental Engineering (ICCEE 2018), (Vol. 65, Article number 04004). EDP Sciences. https://doi.org/10.1051/e3sconf/20186504004

Zhang, J., Xie, H., \& Li, H. (2017). Competency-based knowledge integration of BIM capstone in construction engineering and management education. International Journal of Engineering Education, 33(6), 2020-2032.

Zhang, J., Wu, W., \& Li, H. (2018). Enhancing building information modeling competency among civil engineering and management students with team-based learning. Journal of Professional Issues in Engineering Education and Practice, 144(2), 5018001. https://doi.org/10.1061/(ASCE)EI.1943-5541.0000356

Zhao, D., McCoy, A. P., Bulbul, T., Fiori, C., \& Nikkhoo, P. (2015). Building collaborative construction skills through BIM-integrated learning environment. International Journal of Construction Education and Research, 11(2), 97-120. https://doi.org/10.1080/15578771.2014.986251 